\title{
The construction of "smart campus" and the protection of students' privacy in the age of Internet of things
}

\author{
Yan Hui, Zhang Yuqi, Fan Xinyan, Liu Qian \\ Shandong Women's University, China \\ Email,287077907@qq.com;Email,812382973@qq.com;Email,1628257181@qq.com;Email,133451 \\ 27896@163.com
}

Keywords: Internet of things; Intelligent Campus; Privacy Security.

\begin{abstract}
Development momentum in recent years, the Internet of things technology, has become the important strategic development direction of information emerging industry in China. All walks of life increasingly widespread use of Internet of things technology, the Internet of things development prospect is bright. Colleges and universities are important positions for the delivery of talents for the society, and also a frontier practice for the rapid development of emerging technologies. While smart schools are rife, student personal information is also at risk of being leaked. How to build a "smart campus" to bring convenience to students and to protect the integrity of students' information is a major problem facing colleges and universities.
\end{abstract}

\section{An overview of the Internet of things and "smart campus"}

\subsection{The definition and function of the Internet of things}

The Internet of things, in a nutshell, is a web of interconnections, a network that is based on the Internet and continues to expand and expand. At present, in domestic more see more of the "Internet of things" is defined as: the Internet of things refers to use all kinds of information sensing devices, such as radio frequency identification device, infrared sensors, global position system, laser scanning device such as a variety of combined with Internet and formed a huge network, its purpose is to make all things with the network connection, convenient to identify and manage ${ }^{[1]}$.

\subsection{Smart Campus}

The smart campus is to make full use of the Internet of things technology to realize the intellectualization of campus management. It through the Internet of things built a campus all people and objects, all information carrier, all the time, all sites can be connectivity platform, huge amounts of information in it polymerization to produce new information on the network platform, to the vast number of teachers and students to provide services the needs of the wisdom and convenient management pattern ${ }^{[2]}$. Nowadays the Internet of things technology is still in the preliminary stage of development, technology is not yet ripe for easy to lead to subsequent various problems; On the other hand, if you want to build an intelligent system of campus, teachers and students to the consumer behavior, information resources, such as continuous tracking, forming vast amounts of data. At the same time, if the loopholes in colleges and universities information protection system will directly lead to personal privacy, between teachers and students have adverse consequences. 


\section{Use the Internet of things technology to create a "smart campus"}

\subsection{Use the Internet of things technology to realize smart and fast campus}

A school is a group of independent individuals. "One card walking the campus" seems difficult to achieve. Moreover, in recent years, due to the poor management of businesses in colleges and universities, the enterprise has been closed in the campus industry module, and the phenomenon of "carrying money and running the road" has been frequent. College students have weak ability to protect their rights, and the frequency of such incidents is greatly increased. After the introduction of Internet of things technology, people and objects form an interwoven network, and all data are uploaded to the network to form big data. For students with "all-in-one-card", disperses all the campus card function to merge, through the school unified management, to ensure the safety of the property of the students, as well as to standardize the order of the campus, make the management of colleges and universities more system, convenient.

2.2 Use the Internet of things technology to realize the "no dead Angle" campus monitoring system Using Internet technology to achieve "no dead Angle" campus monitoring system, the realization of digital, intelligent, facilitation of campus security, can greatly satisfy the needs of modern campus, strengthen the construction of campus security. If the perceptual technology, the use of the Internet of things in the wisdom campus, an important official documents and related items, GPS and QR code label can be real-time positioning and search for items, to ensure that important events to implement security management; To timely locate and monitor the vehicles in and out of campus, effectively control the campus traffic flow, and ensure campus security; To install smart sensors for key areas and important facilities to realize security monitoring, if there is any suspicious situation, the sensing point will issue an alarm to the management center and analyze the cause ${ }^{[3]}$.

\subsection{Using IOT technology to realize the digitization of classroom teaching}

Class attendance, should not only take up valuable class time, at the same time, the accuracy of the lack of data, using the Internet of the implementation of intelligent attendance, student credit card into the classroom, the system automatically recognize faces, will check on work attendance form data sent to the teacher. Effectively improve the attendance rate of class.

Through the use of the Internet of things can realize the integration of virtual space and realistic environment, would be to each item in real teaching the visualization, digital and modular, so that the students can be real to touch the virtual space, the theory of the real scene perception books in class, no longer inflexible understanding of theoretical knowledge, but strengthen what they have learned through practice content, widen the channel of the study, at the same time, "smart classrooms" divides the teacher's teaching burden, make the teacher can put more energy in scientific research project and construction of scientific results and make the teaching achievements and scientific research to realize qualitative leap.

\section{The negative impact of IOT on students' privacy security}

"Magnum" is an important symbol of the Internet of things. Using massive data to build a virtual and realistic platform, students can share and use information more easily, but data privacy can be easily leaked. When users use of the Internet of things for communication, the wireless transmission mode makes it easy for the attacker to obtain sensitive information from the signal exchange of the 
transmission node, and to forge it, causing personal loss.

\section{The privacy threat of Internet of things}

\subsection{Analysis of IOT system}

\begin{tabular}{|l|l|}
\hline application layer & $\begin{array}{l}\text { Intelligent transportation, environmental monitoring, } \\
\text { telemedicine, smart home and other processing layer data mining, } \\
\text { intelligent computing, parallel computing, cloud computing, etc. }\end{array}$ \\
\hline transport layer & $\begin{array}{l}\text { WiMAX, GSM, 3G communication network, satellite network, } \\
\text { Internet, etc. }\end{array}$ \\
\hline Perception layer & RFID, QR code, sensor, infrared sensor, GPS, etc. \\
\hline
\end{tabular}

Table 1 Internet of things architecture

The architecture of the Internet of things can be divided into three levels: the ubiquitous terminal perception network, the integrated network communication infrastructure and the universal application service support system. People simply call them the perception layer, the network layer, the application layer.

Application layer: the application of the Internet of things is the "social division of labor", which combines the industry needs and achieves a wide range of intelligence. The application layer is the Internet of things and the depth of the industry professional and technical integration, combined with the industry needs to realize industry intelligent IOT application layer using after analysis and processing of sensory data, to provide users with a specific service.

Transport layer: the network layer is the nerve center of the Internet of things and the brain is used to transmit information and process information. The network layer solves the problem of data acquired by the transport and preprocessing perception layer. Cognitive data management and processing technology in the network layer is the core of the realization of data-centric IOT technology, including the sensor network data storage, query, analysis, mining and understanding, and perception data based decision theory and technology.

Aware of layer: layer is a IOT of skin and facial features, main function is to perception and information acquisition, mainly including QR code device and read labels, RFID tags and read and write, cameras, all kinds of sensors, etc.

\subsection{Privacy threats to the Internet of things}

System level analysis of the above things can be concluded that the Internet privacy protection issues in the perception and processing layer distribution is relatively concentrated, so the Internet privacy threat can be simply divided into two categories:

\subsubsection{Privacy security analysis of the Internet of things application}

In the era of Internet of things, tens of thousands of messages are processed every day, and how to protect the privacy information in the process of participating in the process is the issue of privacy protection. There are many kinds of processing:

The Internet of things to obtain location information is the most basic function. The most important location information is the application of satellite positioning technology to modern electronic maps. 
The Internet of things is easy to get users' location information (including the user's past or present location information), as well as the route the user walks through each day.

Data mining is a process of complex processing and analysis of massive data, which can be used to obtain useful and effective information. Such information can be widely applied in the Internet of things. However, it is inevitable that data loss, misuse and abuse occur in this process, so that users' information will be leaked, resulting in inevitable consequences.

\subsubsection{Privacy security analysis of IOT}

It has privacy security problems of RFID system. Nowadays, RFID technology has been used more and more, and has played an irreplaceable role in manufacturing, retail and logistics, but the security and privacy issues of various kinds of RFID are followed.

In the Internet of things, the application of RFID technology is very wide, almost all can be RFID tags, after is identified as mobile network nodes, which can be traced, tracing, monitoring and trigger events. Radio frequency identification technology in Internet of things applications played an irreplaceable role, but its lack of ability to ensure safety. At the same time, RFID technology (RFID) reader should communicate with the host, and RFID technology can also be an object of attack. Therefore, RFID hinder the development of the Internet of things.

\section{Summary}

In the first two waves of information, China started slowly, and now we have to seize new opportunities to extend modernization and informatization to all walks of life. School, as the mainstream position of information practice and development, more should catch the opportunity of development in the information age, make full use of the beneficial side of Internet of things, and comprehensively promote the construction of campus wisdom, realizing the leapfrog development of a higher level in colleges and universities. But at present, the development of the Internet of things is still in progress, the management mechanism is not perfect, and the construction direction of "smart campus" is also unclear. The way how to perfect the "smart campus" and create a safe and unexploited standard system, we need to constantly explore and innovate.

\section{References}

[1] Ning Huansheng, Xu Qunyu. A number of thoughts on the development of global Internet of things and the construction of Chinese Internet of things [J]. Journal of electronic transactions, 2010, (11):2590-2599.

[2] Yan dong. Intelligent library based on the Internet of things [J]. Library journal, 2010, (7):8-10.

[3] Chen Mingxuan, Xu Yang. Research on the construction and development of intelligent campus based on the Internet of things [J]. Remote education magazine, 2012(4):61-65.

[4] Qian Ping; Wu Meng. Research and methods on privacy protection of Internet of things [J]. Computer application research. January 2013.

[5] Song Chengji. The application of IOT technology in the construction of smart campus [J]. Automation and instrumentation. March 2015. 